\section{Suplementos vitamínicos e/ou minerais: regulamentação, consumo e implicações à saúde}

\author{
Vitamin and mineral supplements: \\ regulation, consumption, and health implications
}

\author{
Suplementos de vitaminas y/o minerales: \\ normativas, consumo e implicaciones en la salud
}

Lucile Tiemi Abe-Matsumoto 1,2 Geni Rodrigues Sampaio 2

Deborah H. M. Bastos 2
1 Núcleo de Química, Física e Sensorial do Centro de Alimentos, Instituto Adolfo Lutz, São Paulo, Brasil.

2 Faculdade de Saúd

Pública, Universidade de

São Paulo, São Paulo, Brasil.

Correspondência

D. H. M. Bastos

Departamento de Nutrição,

Faculdade de Saúde Pública,

Universidade de São Paulo.

Av. Dr. Arnaldo 715,

São Paulo, SP 01246-904,

Brasil.

dmbastos@usp.br

\begin{abstract}
Micronutrient supplementation to reduce nutritional deficiencies has grown in recent years due to changes in the population's dietary patterns. Widespread preoccupation with health, ease in marketing vitamin and mineral supplements, and strong advertising appeal have encouraged increasing consumption of these products, thereby posing health risks. The current study addresses legislation, consumption, and health risks related to vitamin and mineral supplements in Brazil. The Brazilian legislation on dietary supplements is complex. Studies on their consumption by the Brazilian population are limited, and inappropriate use due to gaps in knowledge poses a potential health risk to the population. The study concludes that public policies are needed to raise awareness on this topic among the general public, health professionals, and sales personnel.
\end{abstract}

Dietary Supplements; Vitamins; Food Legislation

\section{Resumo}

Em decorrência das mudanças no padrão alimentar da população, a suplementação da dieta com micronutrientes é prática comum. A preocupação com a saúde e a facilidade de comercialização dos suplementos vitamínicos elou minerais, aliadas ao forte apelo publicitário, têm estimulado a população ao consumo indiscriminado desses produtos, o que pode acarretar riscos à saúde. Este trabalho teve como objetivo avaliar a legislação relativa ao cenário do consumo e segurança do uso de suplementos vitamínicos elou minerais no Brasil. Verificou-se que as legislações brasileiras a esse respeito são complexas, dificultando o entendimento das normas e a aplicação destas. Estudos sobre o consumo de suplementos pela população brasileira são limitados, e o consumo inadequado por falta de conhecimento é um potencial risco à saúde da população. Concluiu-se que há necessidade de implementação de políticas públicas que promovam o esclarecimento da população, dos profissionais da área de saúde e do comércio sobre o assunto.

Suplementos Nutricionais; Vitaminas; Legislação sobre Alimentos 


\section{Introdução}

Nas últimas décadas, tem-se observado, na população brasileira, maior consumo de alimentos processados com alta densidade calórica e pobres em nutrientes essenciais, em substituição ao consumo de alimentos mais nutritivos, como as frutas e as verduras (Instituto Brasileiro de Geografia e Estatística. http://www.ibge. gov.br/home/estatistica/populacao/condicao devida/pof/, acessado em 30/Set/2014) 1. Em decorrência das mudanças no estilo de vida e, consequentemente, no padrão alimentar da população, suplementos vitamínicos e alimentos enriquecidos tornam-se veículos práticos de vitaminas para a população. O aumento da expectativa de vida e a preocupação com uma vida saudável passaram a ser prioridades para uma parcela crescente da população, que está disposta a investir tempo e recursos a fim de viver mais e melhor. A grande variedade de usos terapêuticos aliada ao lucrativo mercado desses produtos estimulam o aumento da publicidade e, consequentemente, o seu consumo com finalidades diversas, tais como retardar o envelhecimento, combater o estresse, prevenir doenças e melhorar a saúde $2,3,4$.

Considerando o significativo aumento no consumo de suplementos vitamínicos e/ou minerais, os possíveis riscos da ingestão indiscriminada e, ainda, a aparente deficiência nas ações de fiscalização, foi avaliado o panorama dos suplementos vitamínicos e/ou minerais no Brasil. Objetivou-se, ainda, esclarecer equívocos de nomenclaturas, por meio da correta interpretação das legislações, e verificar os potenciais riscos à saúde do consumidor.

\section{Aspectos regulatórios}

No Brasil, os produtos à base de vitaminas e minerais são divididos em duas categorias: suplementos vitamínicos e/ou minerais e medicamentos à base de vitaminas e minerais. $\mathrm{O}$ que os diferencia são os níveis de micronutrientes oferecidos na dosagem diária recomendada. Segundo a Portaria no 32/1998 5 da Secretaria de Vigilância em Saúde do Ministério da Saúde (SVS/MS), "suplementos vitamínicos são alimentos que servem para complementar com estes nutrientes a dieta diária de uma pessoa saudável, em casos onde sua ingestão, a partir da alimentação, seja insuficiente ou quando a dieta requerer. Devem conter um mínimo de 25\% e no máximo até $100 \%$ da Ingestão Diária Recomendada (IDR) de vitaminas elou minerais, na porção diária indicada pelo fabricante, não podendo substituir os alimentos, nem serem considerados como dieta exclusiva". Já os medicamentos à base de vitaminas e minerais são definidos como aqueles cujos esquemas posológicos diários situam-se acima dos $100 \%$ da IDR 6 .

O conceito atual de recomendação nutricional é baseado na Dietary Reference Intake (DRI), estabelecida conjuntamente pelos Estados Unidos e Canadá, tendo como referência a população destes países. Tais valores de referência são utilizados na avaliação e planejamento de dietas, com os objetivos de promover a saúde, diminuir o risco de doenças e evitar o consumo excessivo de algum nutriente por um indivíduo ou um grupo. As recomendações nutricionais da DRI compreendem quatro conceitos para consumo de nutrientes: (i) Necessidade Média Estimada (Estimated Average Requirements - EAR); (ii) Ingestão Dietética Recomendada (Recommended Dietary Allowance - RDA); (iii) Ingestão Adequada (Adequate Intake - AI); (iv) Limite Superior Tolerável de Ingestão (Tolerable Upper Intake Level - UL). O UL não é um nível de ingestão recomendado, e seu estabelecimento surgiu como um alerta para se evitar o consumo excessivo de micronutrientes devido ao crescente uso de suplementos nutricionais e de alimentos fortificados 7. A RDC no 360/2003 8 da Agência Nacional de Vigilância Sanitária (ANVISA) estabelece os valores de IDR de nutrientes, tendo como base as recomendações da DRI, porém sua principal finalidade é padronizar, na rotulagem de alimentos, informações quanto à porcentagem de atendimento às necessidades nutricionais.

A legislação brasileira segue a tendência mundial no que diz respeito à preocupação com a qualidade e segurança dos alimentos, estabelecendo cooperações internacionais. O Brasil é membro integrante do MERCOSUL (Mercado Comum do Sul), que, por meio de amplos debates entre os países membros, determina normas, adaptadas às políticas e aos programas públicos de cada país, a fim de estabelecer a livre circulação de alimentos seguros e saudáveis. Na mesma linha de cooperação internacional, o Codex Alimentarius é um programa conjunto da Organização das Nações Unidas para Agricultura (FAO) e Alimentação e da Organização Mundial da Saúde (OMS), criado em 1963, cuja finalidade é proteger a saúde da população e incentivar práticas justas no comércio internacional de alimentos 9 .

Em relação aos suplementos vitamínicos e/ ou minerais, a Portaria no 32/1998 tem como referência as normas do Codex Alimentarius (http:// www.codexalimentarius.org/, acessado em 21/ Jan/2014), que define suplementos de vitaminas e minerais como fontes de nutrientes na forma concentrada, isolados ou em combinação, co- 
mercializados em cápsulas, comprimidos, pós, soluções etc., que são formulados para serem ingeridos em pequenas quantidades, diferindo de alimentos convencionais e cujo propósito seja suplementar a ingestão de vitaminas e/ou minerais na dieta normal. Essa norma estabelece que o teor mínimo de vitaminas e minerais em suplementos, na porção diária sugerida pelo fabricante, deve ser de 15\% da IDR; já a quantidade máxima deve ser estabelecida tendo como critérios níveis seguros de vitaminas e minerais determinados por avaliações de risco baseados em dados científicos e ingestão diária de vitaminas e minerais de outras fontes dietéticas.

O Codex Alimentarius tornou-se referência mundial para os consumidores, produtores de alimentos e para os organismos internacionais de controle e comércio de alimentos. Sua influência se estende a todos os continentes, oferecendo aos países a oportunidade de se unirem à comunidade internacional, com o objetivo de formular e harmonizar as normas alimentares. A harmonização dessas normas ajuda a eliminar as barreiras comerciais e permite maior liberdade de comércio de alimentos entre os países.

O Food and Drug Administration (FDA) é o órgão governamental dos Estados Unidos responsável pelo controle de alimentos e medicamentos, promovendo a proteção da saúde da população. Segundo o FDA (http://www.fda. gov/food/dietarysupplements/consumerinfor mation/ucm191930.htm, acessado em 05/Ago/ 2014), suplementos dietéticos são produtos que podem conter múltiplos ingredientes, incluindo vitaminas, minerais, ervas, aminoácidos, substâncias dietéticas para suplementar a dieta aumentando a ingestão dietética total, concentrados, metabólitos, constituintes e extratos, a combinação de um ou mais destes ingredientes, não existindo definição legal e classe específica para suplementos vitamínicos e/ou minerais. No Brasil, os produtos definidos como suplementos dietéticos pelo FDA são subdivididos de acordo com legislações específicas, abrangendo uma classificação muito mais ampla, os quais estão descritos na Tabela 1 .

No nosso país, legalmente, o conceito de suplemento se restringe aos alimentos para atletas 10 e aqueles à base de vitaminas e minerais 5 , foco deste artigo. Segundo a $R D C$ no 18/2010 10, os alimentos para atletas podem, ainda, ser compostos por vitaminas e minerais, conforme regulamento técnico específico sobre adição de nutrientes essenciais. A complexidade na classificação desses produtos faz com que aqueles que tenham algum apelo voltado à saúde ou a finalidade de suplementar a dieta, sejam denominados de suplemento; assim, com esta deno- minação, são frequentemente anunciados nos informes publicitários.

Em relação à rotulagem de suplementos vitamínicos, além das exigências de rotulagem gerais para alimentos, a Portaria $n^{\circ} 32 / 1998$ estabelece algumas determinações específicas, tais como a obrigatoriedade de destacar em negrito as expressões: "Consumir este produto conforme a Recomendação de Ingestão Diária constante da embalagem" e "Gestantes, nutrizes e crianças até 3 (três) anos somente devem consumir este produto sob orientação de nutricionista ou médico". Diferentemente dos medicamentos, os suplementos não apresentam funções curativas, sendo, portanto, proibida toda e qualquer expressão que se refira ao uso do suplemento para prevenir, aliviar, tratar uma enfermidade, ou alterar o estado fisiológico 5. Já os medicamentos à base de vitaminas e minerais devem apresentar a denominação "polivitamínicos e/ou poliminerais", porém não se exige que conste no rótulo a palavra "medicamento", dificultando a distinção entre suplemento e medicamento 11 .

Segundo o Código de Defesa do Consumidor 12 , todo o produto deve trazer informações claras, precisas e em língua portuguesa, sendo que os rótulos de alimentos, os quais incluem os suplementos vitamínicos, devem indicar o prazo de validade, quantidade, ingredientes, nome e endereço do fabricante, entre outros dados, como forma de conservação e de consumo. As informações constantes na rotulagem dos alimentos são de extrema importância, visto que a informação é um dos direitos básicos do consumidor. É por meio da rotulagem que os consumidores são orientados a escolher produtos que contribuam para sua adequada alimentação, além de se conscientizarem sobre o que estão ingerindo.

\section{Fiscalização}

Os suplementos vitamínicos e minerais, juntamente com outras 14 categorias de produtos, foram classificados como alimentos de baixo risco pela ANVISA e passaram a ser dispensados de registro sanitário a partir de 2010 13. Segundo a ANVISA, pretendia-se otimizar as ações de controle sanitário, focando na análise e fiscalização dos alimentos expostos ao consumo da população, já que o volume de pedidos de registro era muito alto, e a finalização de um processo de registro chegava a demorar até dois anos 14 .

Os produtos alimentícios de competência da ANVISA são divididos em dois grupos: alimentos com registro obrigatório prévio à comercialização e alimentos dispensados da obrigatorieda- 
Tabela 1

Portarias e Resoluções que aprovam o regulamento técnico para cada classe de produtos.

\begin{tabular}{|c|c|c|}
\hline Legislações & Regulamento técnico aprovado & Subclassificação ou exemplos de produtos \\
\hline \multirow[t]{3}{*}{ Portaria no 32/1998 5} & Suplemento vitamínico e/ou mineral & Suplemento de vitaminas e/ou minerais \\
\hline & & Suplemento de vitaminas \\
\hline & & Suplemento de minerais \\
\hline \multirow[t]{3}{*}{ RDC no 18/1999 50} & Alimento com alegações de propriedades & Óleo de peixe \\
\hline & funcionais e/ou de saúde & Carotenóides \\
\hline & & (licopeno, luteína e zeaxantina) \\
\hline \multirow[t]{2}{*}{ RDC no 16/1999 51} & Novo alimento & Óleo de cártamo \\
\hline & & Óleo de prímula \\
\hline \multirow[t]{7}{*}{$R D C$ no 18/2010 10} & Alimento para atleta & Suplemento hidroeletrolítico para atletas \\
\hline & & Suplemento energético para atletas \\
\hline & & Suplemento proteico para atletas \\
\hline & & Suplemento para substituição parcial de \\
\hline & & refeições de atletas \\
\hline & & Suplemento de creatina para atletas \\
\hline & & Suplemento de cafeína para atletas \\
\hline
\end{tabular}

de de registro, conforme estabelecido na $R D C$ no $27 / 2010$ 13. A solicitação de registro de um produto é efetuada pela empresa interessada, junto ao órgão de Vigilância Sanitária local, mediante apresentação de documentos específicos e formulários de petição, além de pagamento de taxa. Para os produtos dispensados da obrigatoriedade de registro, a empresa deve somente informar o início da fabricação ao órgão de Vigilância Sanitária, podendo dar início imediato à comercialização. A autoridade sanitária terá um prazo de sessenta dias para proceder à inspeção na unidade fabril, e a empresa terá um prazo de trinta dias para solicitar à Coordenação de Vigilância em Saúde (COVISA) que proceda à coleta de amostra, visando a uma análise de controle, ou seja, a uma análise a ser realizada em um laboratório de referência. No caso de a empresa e/ ou de o produto estarem em desacordo com as legislações vigentes, aquela será notificada para suspender a produção, recolher os produtos do mercado e notificar a população. Para os suplementos importados, o importador ou a empresa representante no Brasil será responsável por enquadrá-los na categoria prevista na legislação, responsabilizando-se, ainda, por comunicar a importação de produtos dispensados de registro; no caso dos medicamentos, deve registrá-los no Ministério da Saúde 14.

A isenção de registro sanitário para algumas categorias de alimentos é um fato questionável, já que a ANVISA exige que as empresas busquem a melhor forma de disponibilizar um alimento com mínimo risco para o consumidor. Além dos suplementos vitamínicos e minerais, outra categoria cuja isenção de registro é questionável é a dos alimentos para atletas. Em estudo realizado por Yano et al. 15, verificou-se presença de substâncias ativas não declaradas no rótulo, como a metoclopramida e o cloridrato de sibutramina, em amostras de alimentos para atleta coletadas pela Vigilância Sanitária e pelo Departamento de Polícia do Estado de São Paulo. Com a isenção de registro, há necessidade de efetiva fiscalização destes produtos por parte da Vigilância Sanitária, pois estarão sendo consumidos pela população antes de qualquer verificação. O registro no Ministério da Saúde garante-lhes maior confiabilidade, já que, entre as documentações solicitadas para o seu registro, constam a licença de funcionamento da empresa, aprovação do local de produção na inspeção sanitária, sendo exigido, ainda, um laudo oficial de análise do produto antes da comercialização 14 . No caso dos produtos isentos, uma parcela da população já terá consumido o produto se for detectada qualquer inconformidade neste ou no local de fabricação.

Em relação aos produtos importados, somente a legislação brasileira estabelece limite de $100 \%$ da IDR para suplementos vitamínicos e/ou minerais ${ }^{5}$. Sendo assim, produtos importados contendo maior teor de micronutrientes (acima de $100 \%$ da IDR), no Brasil, seriam classificados 
como medicamentos e estariam sujeitos à obrigatoriedade de registro. Existem, no mercado nacional, diversos produtos importados dos Estados Unidos ou do Canadá, por exemplo, países nos quais a dosagem máxima de micronutrientes em suplementos dietéticos não é limitada a 100\% da IDR; ao serem exportados para o Brasil como suplementos, as empresas importadoras apenas os rotulam como suplementos vitamínicos e/ou minerais, comercializando-os sem registro prévio, ou seja, sem a verificação da real concentração de micronutrientes presente (http:// www.fda.gov/food/dietarysupplements/consu merinformation/ucm191930.htm, acessado em 05/Ago/2014) 5. Neste caso, cabe às autoridades da Vigilância Sanitária proceder à fiscalização desses produtos, notificando a empresa para que suspenda a produção e os recolha do mercado, além de informar a população.

\section{Consumo de suplementos vitamínicos e/ou minerais: panorama nacional e internacional}

O consumo de produtos à base de vitaminas e minerais é amplamente difundido em países como os Estados Unidos e Alemanha 16. No Brasil, informações sobre a extensão e frequência de consumo desses produtos são escassas, porém alguns estudos disponíveis, apesar de restritos a determinados segmentos da população, mostram que o consumo de suplementos vitamínicos e/ou minerais chega a ser comparável ao encontrado nos Estados Unidos 17,18.

Santos \& Barros Filho ${ }^{19}$ verificaram que cerca de $30 \%$ dos universitários de uma universidade privada faziam uso de algum produto vitamínico, a maioria consumindo multivitamínicos, seguidos de suplementos de vitamina C. Neste estudo, não foram obtidas informações sobre a dosagem consumida, não sendo possível concluir se os produtos vitamínicos referiam-se a suplementos ou medicamentos. Há maior prevalência de consumo de suplementos entre os frequentadores de academias, os quais buscam suplementação com objetivos específicos, tais como aumentar a massa muscular, repor perdas e melhorar o desempenho no exercício físico. Trata-se de propósitos típicos dessa população, principalmente do público masculino, fato que já foi confirmado em algumas cidades de São Paulo 17,18,20. Ao contrário, quando se avalia a população em geral, observa-se baixa prevalência de consumo de suplementos, que ainda é maior entre o público feminino, possivelmente porque as mulheres têm preocupação maior com a saúde; ademais, existem, ainda, recomendações específicas para as mulheres, como a suplementação de ácido fólico e ferro durante o período reprodutivo 2,21.

Observou-se, também, que, em trabalhos recentes, a prevalência de consumo de suplementos é maior em comparação à encontrada em trabalhos realizados há cerca de uma década, sendo possível presumir que houve aumento no consumo de suplementos pela população 17,18,20,22. Estes artigos avaliaram o consumo de produtos categorizados como suplementos nutricionais, suplementos alimentares, suplementos dietéticos ou simplesmente suplementos, impossibilitado discriminar se o consumo se referia a suplemento vitamínico e/ou mineral, alimento para atleta, ou medicamento. Tais categorias não estão previstas na lei brasileira, assim como não estão previstas nos regulamentos técnicos da ANVISA. Além disso, a população de estudo era restrita e específica.

O único estudo disponível no Brasil sobre consumo de suplementos alimentares numa população heterogênea foi realizado por Brunacio et al. 23 , no qual se observaram $6,35 \%$ de prevalência de consumo de suplementos alimentares na população residente no Município de São Paulo. Os suplementos compostos por vitaminas, minerais e multivitamínicos lideraram o uso. Os autores concluíram que essa prevalência é similar à encontrada na Grécia, Espanha e Itália, e menor que a verificada nos Estados Unidos, Reino Unido, Suécia e Alemanha.

O National Health and Nutrition Examination Survey (NHANES) é um programa que avalia o estado nutricional de adultos e crianças nos Estados Unidos, por meio de entrevista e exame físico. O NHANES faz parte do Centers for Disease Control and Prevention (CDC) e tem a responsabilidade de produzir estatísticas de vida e de saúde para a nação ${ }^{24}$. De acordo com esse programa, observou-se que $40 \%$ da população americana consumia um ou mais suplemento dietético durante o período de 1988 a 1994; entre 2003 e 2006, essa prevalência passou a ser superior a $50 \%$. Os multivitamínicos/multiminerais foram o tipo de suplemento mais reportado em todas as pesquisas realizadas pelo NHANES 25.

No Brasil, a Pesquisa de Orçamentos Familiares (POF) é a pesquisa domiciliar por amostragem que avalia, principalmente, o orçamento domiciliar, mas também permite obter informações sobre consumo alimentar da população e prevalência de inadequação do consumo de nutrientes (Instituto Brasileiro de Geografia e Estatística. http://www.ibge.gov.br/home/esta tistica/populacao/condicaodevida/pof/, acessado em 30/Set/2014). Apesar de sua abrangência nacional, não há qualquer menção sobre suplementos, não sendo possível verificar o real con- 
sumo de suplementos vitamínicos e/ou minerais pela população brasileira.

Em 2003, o mercado que engloba vitaminas, minerais, fitoterápicos e suplementos nutricionais faturou aproximadamente 10 bilhões de dólares nos Estados Unidos, sendo esse mercado composto principalmente por multivitamínicos, suplementos vitamínicos e bebidas destinadas a atletas. Em 2007, o faturamento anual foi maior que 30 bilhões de dólares 26 . Em 2010 e 2011, estudos realizados pela Euromonitor International demonstraram que 175 bilhões de dólares foram gastos no mundo em suplementos vitamínicos e minerais, enquanto suplementos para atletas movimentaram cinco bilhões de dólares 27 .

No Brasil, o faturamento do comércio de complementos vitamínicos aumentou quase $55 \%$ em apenas quatro anos 26. Segundo a Associação Brasileira dos Fabricantes de Suplementos (BRASNUTRI), de 2008 até 2012, houve aumento no faturamento, de 150 milhões de reais para 600 milhões de reais, com uma média de crescimento de $15 \%$ ao ano. A indústria de suplementação teve um crescimento de $21 \%$ em sua produção no ano de 2013, com faturamento médio de um bilhão de reais, e a expectativa para o setor é atingir $15 \%$ de crescimento em 201428.

As projeções dos principais fabricantes indicam que o consumo de complementos vitamínicos continua em ascensão 26 . A forte expansão do mercado de produtos vitamínicos é o principal indício de aumento no consumo destes pela população brasileira.

\section{Cenário atual: há necessidade de consumo de suplementos?}

Novos produtos à base de vitaminas e minerais são frequentemente lançados no mercado, sendo visível o aumento da oferta de suplementos vitamínicos e/ou minerais no comércio. Esse crescimento certamente foi impulsionado pela isenção da obrigatoriedade de registro no Ministério da Saúde 13.

Há algum tempo, a importância das vitaminas era atribuída somente às funções nutritivas e de prevenção de doenças decorrentes de sua deficiência. Recentemente, diversas pesquisas têm se concentrado no papel que esses micronutrientes desempenham na manutenção da saúde, especificamente na redução do risco de desenvolvimento de patologias crônicas, como doenças coronarianas, câncer e diabetes. Muitas dessas investigações têm como foco os alimentos que contêm vitaminas $\mathrm{C}$ e E, além de betacaroteno, precursor da vitamina $\mathrm{A}$, reconhecidos por apresentarem atividade antioxidante, exercendo importante função de defesa do organismo contra os radicais livres 29,30,31. Hoje, é comum observar no mercado uma categoria de suplementos vitamínicos com apelo comercial de antioxidantes.

Assim como as vitaminas antioxidantes, a vitamina D também tem sido alvo de muitas pesquisas nos últimos anos. Embora sua função de manter o metabolismo do cálcio e de prevenir o raquitismo tenha sido descrita pela primeira vez há cerca de cem anos, estudos atuais têm relacionado a deficiência de vitamina $\mathrm{D}$ com o desenvolvimento de várias doenças, como diabetes tipo II, esclerose múltipla, doença inflamatória intestinal, lúpus eritematoso sistêmico e artrite reumatoide 32 . Nos últimos anos, a deficiência de vitamina $\mathrm{D}$ tem aumentado em virtude dos hábitos da vida moderna e principalmente por causa do tempo limitado de exposição ao sol pela população, a fim de evitar câncer de pele 33 . Seguindo essa tendência, foram lançados diversos suplementos à base de vitamina D no mercado, alguns específicos para o público infantil e outros destinados ao uso adulto.

Durante várias décadas, defendeu-se a utilização de suplementos de cálcio para prevenção e tratamento da osteoporose, porém estudos recentes demonstraram que esse uso pode aumentar o risco de eventos cardiovasculares, formação de cálculos renais e causar problemas gastrointestinais 34,35 . Após revisar mais de mil estudos sobre suplementação com cálcio e vitamina D e os possíveis efeitos adversos do consumo em excesso, o Institute of Medicine (Estados Unidos) publicou, em 2010, novas recomendações de cálcio e vitamina D 36. Pesquisas demonstraram que indivíduos saudáveis que ingerem as recomendações de cálcio e vitamina $\mathrm{D}$ na dieta e se expõem ao sol não necessitam de suplementos para manter a saúde óssea; no entanto, a dieta da população brasileira tem se mostrado muitas vezes inadequada com relação ao consumo de cálcio e vitamina $\mathrm{D}$, levando à necessidade de suplementação 33. O cálcio com a vitamina D é uma das associações mais comuns de nutrientes em suplementos, já que esta vitamina age como um hormônio fundamental para a homeostase do cálcio e para o desenvolvimento saudável do sistema ósseo 36,37 .

\section{Riscos à saúde}

A quantidade de micronutrientes necessária para cada indivíduo depende de vários fatores, tais como sexo, idade, nível de atividade física, presença de patologias, entre outros. Em geral, não há necessidade de se fazer suplementação 
de qualquer nutriente quando se tem uma dieta equilibrada e hábitos de vida saudáveis. Como consta em sua definição, suplementos vitamínicos e/ou minerais são indicados somente para pessoas que necessitem complementar a dieta caso a ingestão não seja suficiente, já que a carência de nutrientes pode levar ao desenvolvimento de doenças. A carência de vitamina A, por exemplo, leva ao desenvolvimento da cegueira noturna; a falta de vitamina $\mathrm{C}$ é responsável pelo escorbuto; a deficiência de ferro causa a anemia ferropriva 38 .

Atualmente, a deficiência de vitamina D é considerada uma epidemia, e a suplementação desta vitamina tem sido cada vez mais recomendada 39. A suplementação com micronutrientes pode ajudar a evitar o desenvolvimento de doenças, contudo sua ingestão excessiva, principalmente das vitaminas lipossolúveis, pode trazer consequências à saúde, causando diversos problemas, como danos hepáticos, descamação na pele, enxaqueca e vômito 40 . Têm sido relatados alguns casos de intoxicação por excesso de vitamina $\mathrm{D}$, principalmente em crianças. Araki et al. ${ }^{41}$ reportaram dois casos em crianças por erro do fabricante na formulação e na recomendação de ingestão, resultando em hipercalcemia e sintomas como náusea, poliúria e fadiga após consumirem uma quantidade aproximadamente mil vezes acima da dose recomendada. Kara et al. 42 observaram sete casos de intoxicação por vitamina $\mathrm{D}$ em crianças, em decorrência de erro de fabricação de um suplemento de óleo de peixe. O produto apresentou dose excessivamente alta de vitamina $\mathrm{D}$, causando hipercalcemia, perda de apetite, vômito, perda de peso e constipação após a ingestão de uma quantidade 4 mil vezes superior à dose indicada.

Na década de 1980, diversos estudos epidemiológicos reconheceram o beta-caroteno e o alfa-tocoferol como fatores de proteção contra o desenvolvimento de câncer por suas propriedades antioxidantes, mas os resultados se mostraram controversos 43,44. Conclusões consistentes sobre o papel protetor desses antioxidantes na prevenção do câncer foram obtidas somente a partir de 1994 com o The Alpha-Tocopherol, BetaCarotene (ATBC) Lung Cancer Prevention Study, ensaio clínico em larga escala, o qual testou a hipótese de que o aumento no consumo de alfa-tocoferol e/ou beta-caroteno em fumantes poderia prevenir o câncer de pulmão e outros tipos de câncer. Porém, os resultados demonstraram que a incidência de câncer de pulmão aumentou $17 \%$ entre a população que recebeu suplementação de beta-caroteno ${ }^{45}$. Outro estudo, denominado The Beta-Carotene and Retinol Efficacy Trial (CARET), demonstrou que a suplementação de beta-caroteno e retinol aumentou em $28 \%$ a incidência de câncer no grupo suplementado 46. Algumas críticas a estes estudos estão relacionadas à dose utilizada para suplementação, que claramente ultrapassou a quantidade que seria ingerida por meio de fontes alimentares; além disso, já foi demonstrado que altas doses de antioxidantes podem agir como pró-oxidantes 47 . Portanto, toda suplementação deve ser cautelosa, para se evitarem riscos desnecessários à saúde.

Suplementos vitamínicos comerciais analisados quanto aos teores de vitaminas A e E, utilizando técnica de cromatografia líquida com detecção por arranjo de diodos e espectrometria de massas, mostraram resultados preocupantes, pois os valores verificados diferiram dos declarados no rótulo entre $46 \%$ e $245 \% 48$. No Brasil, não existem ainda análises confrontando os teores encontrados com os declarados nos rótulos de suplementos vitamínicos. É evidente a necessidade de fiscalização imediata desses produtos após a notificação de início da comercialização. As vigilâncias sanitárias de estados e municípios têm autonomia administrativa; ademais, os estados têm laboratórios públicos, os quais devem garantir a qualidade desses suplementos, incluindo o controle da conformidade entre os teores declarados e os apresentados para consumo. Tal controle é de extrema importância, já que a legislação (RDC no 27/2010 13) permite a isenção de registro, mas não permite que o teor de vitaminas e minerais nesses produtos seja livre.

\section{Considerações finais}

Nota-se dificuldade, por parte tanto dos profissionais de saúde e do comércio, como dos consumidores, em se diferenciar o que é suplemento vitamínico e/ou mineral de medicamento à base de vitaminas e/ou minerais. Esse quadro pode levar os consumidores mais desavisados ao risco de consumir produtos com doses acima das recomendadas, sem real necessidade.

Não é raro observar, no comércio, ambas as categorias de produtos dispostas à venda na mesma prateleira, verificando-se total desconhecimento por parte de comerciantes e profissionais de saúde, confundindo ainda mais os consumidores leigos. Ressalta-se a importância de se diferenciarem os suplementos dos medicamentos, uma vez que as dosagens de micronutrientes contidos nos medicamentos são sempre muito superiores às IDRs, podendo ser prejudiciais à saúde de quem os ingere sem a real necessidade e sem a devida orientação, causando problemas de intoxicação. Sugere-se que os profissionais de saúde, principalmente médicos, farmacêuticos 
e nutricionistas, sejam orientados por seus conselhos de classe quanto à diferenciação entre suplementos e medicamentos, essencial para que o profissional esteja apto a indicar ou recomendar o produto que melhor atenda às necessidades do consumidor.

A publicação de uma RDC que regulamente todos os produtos em uma categoria única denominada suplemento dietético, como acontece em outros países, resultaria na definição de uma legislação estável e harmonizada com os principais órgãos reguladores do mundo, facilitando o seu entendimento. Esse tipo de regulamentação é também encontrado em outros países, como os da União Europeia, Estados Unidos, Chile, Argentina, México, Colômbia, além dos países do continente asiático, como o Japão e a Coreia do Sul, entre outros 49. A padronização é importante, tanto para a comercialização de produtos entre os países, quanto para facilitar o entendimento do consumidor. As doses de vitaminas e minerais para os suplementos devem ser definidas como um valor que represente um consumo seguro para a população, independentemente de se seguir o Codex Alimentarius ou o FDA. No caso dos medicamentos, estes deveriam ser prescritos somente em caso de deficiência ou necessidades específicas, estabelecendo-se uma dose superior

Estudos sobre o consumo de suplementos pela população brasileira são escassos, havendo uma lacuna quando se tenta comparar tais dados com os de estudos americanos. Todavia, o faturamento da indústria de produtos vitamínicos o forte apelo publicitário e o visível aumento na oferta de suplementos no mercado indicam aumento no consumo desses produtos.

Portanto, a falta de estudos suficientes e conclusivos sobre suplementos vitamínicos e/ou minerais deve-se não ao fato de ser um assunto recente, mas, principalmente, ao constante aparecimento de novos produtos no mercado. Políticas públicas que promovam campanhas de esclarecimento a respeito do consumo de suplementos são necessárias e urgentes, já que o consumo desse tipo de produto parece ser significativo na população brasileira. É preciso garantir a saúde reduzindo o risco de consumo de suplementos em excesso.

\section{Resumen}

Como resultado de los cambios en los hábitos alimenticios de la población, el consumo de suplementos alimenticios con micronutrientes es una práctica común. La preocupación sobre la salud y la comercialización de suplementos de vitaminas y/o minerales, combinadas con el fuerte atractivo de la publicidad, han animado a la población al consumo indiscriminado de estos productos, que pueden ocasionar riesgos a la salud. Este trabajo tuvo como objetivo evaluar la legislación existente, en relación con el consumo y seguridad en el uso de suplementos de vitaminas y/o minerales. Se descubrió que la legislación brasileña -en materia de suplementos alimenticios- es compleja y difícil de entender, así como la aplicación de la normativa. Los estudios de su consumo por parte de la población son limitados, $y$ el consumo inadecuado por falta de conocimientos es un riesgo potencial para la salud pública. Se concluye que existe la necesidad de implementar políticas públicas que promuevan la transparencia de la información a la población, profesionales de la salud y comercio sobre este tema.

Suplementos Dietéticos; Vitaminas; Legislación sobre Alimentos

\section{Colaboradores}

L. T. Abe-Matsumoto participou da concepção e de todas as etapas de produção do artigo, sendo responsável pela sua redação. G. R. Sampaio realizou o planejamento, a elaboração do rascunho e a revisão crítica do conteúdo; aprovou a versão final do manuscrito. D. H. M. Bastos participou da concepção e planejamento do artigo, da revisão crítica do conteúdo e da aprovação da versão final do manuscrito.

\section{Agradecimentos}

À Fundação de Amparo à Pesquisa do Estado de São Paulo (FAPESP), pelo auxílio financeiro (processo FAPESP 2013/23006-4). 


\section{Referências}

1. Monteiro CA, Levy RB, Claro RM, Castro IRR, Cannon $\mathrm{G}$. Increasing consumption of ultra-processed foods and likely impact on human health: evidence from Brazil. Public Health Nutr 2010; 14:5-13.

2. Bailey RL, Gahche JJ, Miller PE, Thomas PR, Dwyer JT. Why US adults use dietary supplements. JAMA Intern Med 2013; 173:355-61.

3. Oakes ME, Slotterback CS, Bator T, Corrigan ER, Alaimo S, Vagner E. The vitamin mystique: an analysis of beliefs and reputations of vitamin supplements among a regional sample of grocery shoppers. Food Qual Prefer 2005; 16:151-5.

4. Schroeter C, Anders S, Carlson A, Rickard B. The economics of health behavior and vitamin consumption. The economics of food, food choice and health. Freising: AAEA; 2010.

5. Ministério da Saúde. Portaria no 32, de 13 de janeiro de 1998. A Agência Nacional de Vigilância Sanitária aprova o regulamento técnico para fixação de identidade e qualidade de suplementos vitamínicos e ou de minerais. Diário Oficial da União 1998; 15 jan.

6. Ministério da Saúde. Portaria no 40, de 13 de janeiro de 1998. A Agência Nacional de Vigilância Sanitária aprova o regulamento que estabelece normas para níveis de dosagens diárias de vitaminas e minerais em medicamentos. Diário Oficial da União 1998; 15 jan.

7. Cominetti C, Cozzolino SMF. Parte 1: recomendações de nutrientes. In: Cozzolino SMF, organizadora. Biodisponibilidade de nutrientes. 3a Ed. São Paulo: Manole; 2009. p. 12-45.

8. Ministério da Saúde. Resolução RDC no 360, de 23 de dezembro de 2003. Aprova o regulamento técnico sobre rotulagem nutricional de alimentos embalados, tornando obrigatória a rotulagem nutricional. Diário Oficial da União 2003; 26 dez.

9. Costarrica ML, Dawson R. La normalización de alimentos y el Codex Alimentarius en el marco del Mercosur. http://www.fao.org/docrep/v9723t/ v9723t0b.htm (acessado em 20/Out/2014).

10. Ministério da Saúde. Resolução RDC no 18, de 27 de abril de 2010. A Agência Nacional de Vigilância Sanitária aprova o regulamento técnico sobre alimentos para atleta. Diário Oficial da União 2010; $28 \mathrm{abr}$

11. Ministério da Saúde. Resolução RDC no 71, de 22 de dezembro de 2009. Aprova o regulamento técnico que estabelece as diretrizes para a rotulagem de medicamentos. Diário Oficial da União 2009; 23 dez.

12. Brasil. Código de Defesa do Consumidor. Lei no 8.078, de 11 de setembro de 1990. Diário Oficial da União 1990; 12 set.

13. Ministério da Saúde. Resolução RDC no 27, de 6 de agosto de 2010. A Agência Nacional de Vigilância Sanitária dispõe sobre as categorias de alimentos e embalagens isentos e com obrigatoriedade de registro sanitário. Diário Oficial da União 2010; 9 ago.
14. Agência Nacional de Vigilância Sanitária. Isenção e obrigatoriedade de registro de produtos da área de alimentos. http://portal.anvisa.gov.br/wps/ content/Anvisa+Portal/Anvisa/Inicio/Alimentos/ Assuntos+de+Interesse/Registro (acessado em 22/ Set/2014).

15. Yano HM, Guardia RCA, Auricchio MT. Detecção de sibutramina e metoclopramida em alimentos para atleta. Rev Inst Adolfo Lutz 2011; 70:599-605.

16. Soni MG, Thurmond TS, Miller ER, Spriggs T, Bendich A, Omaye S. Safety of vitamins and minerals: controversies and perspective. Toxicol Sci 2010; 118:348-55

17. Alves SCR, Navarro F. O uso de suplementos alimentares por frequentadores de academias de Potim-SP. Revista Brasileira de Nutrição Esportiva 2010; 4:139-46.

18. Fayh APT, Silva CV, Jesus FRD, Costa GK. Consumo de suplementos nutricionais por frequentadores de academias da cidade de Porto Alegre. Rev Bras Ciênc Esporte 2013; 35:27-37.

19. Santos MO, Barros Filho AA. Consumo de produtos vitamínicos entre universitários de São Paulo, SP. Rev Saúde Pública 2002; 36:250-3.

20. Pereira RF, Lajolo FM, Hirschbruch MD. Consumo de suplementos por alunos de academias de ginástica em São Paulo. Rev Nutr 2003; 16:265-72.

21. Vasconcelos FAG. Avaliação nutricional de coletividades. 4a Ed. Florianópolis: Editora UFSC; 2008.

22. Hirschbruch MD, Fisberg M, Mochizuki L. Consumo de suplementos por jovens frequentadores de academias de ginástica em São Paulo. Rev Bras Med Esporte 2008; 14:539-43.

23. Brunacio KH, Verly-Jr E, Cesar CLG, Fisberg RM, Marchioni DM. Uso de suplementos dietéticos entre residentes do Município de São Paulo, Brasil. Cad Saúde Pública 2013; 29:1467-72.

24. Centers for Disease Control and Prevention. About the National Health and Nutrition Examination Survey. http://www.cdc.gov/nchs/nhanes/about_ nhanes.htm (acessado em 03/Fev/2014)

25. Gahche J, Bailey R, Burt V, Hughes J, Yetley E, Dwyer J, et al. Dietary supplement use among U.S adults has increased since NHANHES III (19881994). Hyattsville: National Center for Health Statistics; 2011

26. Servico Brasileiro de Apoio às Micro e Pequenas Empresas. Prioridade à saúde. http://www2. rj.sebrae.com.br/boletim/prioridade-a-saude/ (acessado em 02/Jun/2012).

27. Euromonitor International. Sports nutrition in Brazil. http://www.euromonitor.com/sports-nutri tion-in-brazil/report (acessado em 15/Ago/2014).

28. Associação Brasileira dos Fabricantes de Suplementos. Os mercados que mais crescerão no Brasil em 2014. http://brasillink.usmediaconsulting com/2014/03/os-mercados-que-mais-cresceraono-brasil-em-2014/ (acessado em 04/Nov/2014). 
29. Boni A, Pugliese C, Cláudio CC, Patin RV, Oliveira FLC. Vitaminas antioxidantes e prevenção da arteriosclerose na infância. Rev Paul Pediatr 2010; 28:373-80.

30. Farbstein D, Kozak-Blickstein A, Levy AP. Antioxidant vitamin and their use in preventing cardiovascular disease. Molecules 2010; 15:8098-10.

31. Ryan MJ, Dudash HJ, Docherty M, Geronilla KB, Baker BA, Haff GG, et al. Vitamin E and C supplementation reduces oxidative stress, improves antioxidant enzymes and positive muscle work in chronically loaded muscles of aged rats. Exp Gerontol 2010; 45:882-95.

32. Dobnig H. A review of the health consequences of the vitamin D deficiency pandemic. J Neurol Sci 2011;311:15-8.

33. Unger MD, Cuppari L, Titan SM, Magalhães MCT, Sassaki AL, Reis LM, et al. Vitamin D status in a sunny country: where has the sun gone? Clin Nutr 2010; 29:784-8.

34. Bolland MJ, Grey A, Avenel A, Reid IR. Calcium supplements increase risk of myocardial infarction. J Bone Miner Res 2015; 30:389-90.

35. Taksande SR, Worcester EM. Calcium supplementation in chronic kidney disease. Expert Opin Drug Saf 2014; 13:1175-85.

36. Nestle M, Nesheim MC. To supplement or not to supplement: the US preventive services task force recommendations on calcium and vitamin D. Annals Intern Med 2013; 158:701-3.

37. Barbosa AM, Nunes IFOC, Carvalho LR, Figueiredo RG, Nogueira AMT, Carvalho CMRG. Ingestão alimentar de cálcio e vitamina $\mathrm{D}$ e associação com o nível de escolaridade na pessoa idosa. Demetra 2013; 8:173-81.

38. Mahan LK, Escott-Stump S, Raymond JL. Krause alimentos, nutrição e dietoterapia. 11ạ Ed. São Paulo: Roca; 2010.

39. Kuriacose R, Olive KE. Vitamin D insufficiency/deficiency management. South Med J 2014; 107:66-70.

40. FAO/WHO Expert Consultation on Human Vitamin and Mineral Requirements. Vitamin and mineral requirements in human nutrition: report of a joint FAO/WHO expert consultation. 2nd Ed. Bangkok: Food and Agriculture Organization of the United Nations; 2004.

41. Araki T, Holick MF, Afonso BD, Charlap E, Romero CM, Rizk D, et al. Vitamin D intoxication with severe hypercalcemia due to manufacturing and labeling errors of two dietary supplements made in the United States. J Clin Endocrinol Metab 2011; 96:3603-8.
42. Kara C, Gunindi F, Ustyol A, Aydin M. Vitamin D intoxication due to an erroneously manufactured dietary supplement in seven children. Pediatrics 2014; 133:240-4.

43. Menkes MS, Comstock GW, Vuilleumier JP, Helsing KJ, Rider AA, Brookmeyer R. Serum beta-carotene, vitamins A and E, selenium, and the risk of lung cancer. N Engl J Med 1986; 315:1250-4.

44. Peto R, Doll R, Buckley JD, Sporn MB. Can dietary beta-carotene materially reduce human cancer rates? Nature 1981; 290:201-8.

45. Heinonen OP, Huttunen JK, Albanes D. The effect of vitamin $\mathrm{E}$ and beta-carotene on the incidence of lung cancer and other cancers in male smokers. $\mathrm{N}$ Engl J Med1994; 330:1029-35.

46. Omenn GS, Goodman G, Thornquist M, Grizzle J, Rosenstock L, Barnhart S, et al. The beta-carotene and retinol efficacy trial (CARET) for chemoprevention of lung cancer in high risk populations: smokers and asbestos-exposed workers. Cancer Res 1994; 54(7 Suppl):2038s-43s.

47. Pearson P, Lewis AS, Britton J, Young IS, Fogarty A. The pro-oxidant activity of high-dose vitamin $\mathrm{E}$ supplements in vivo. Biodrugs 2006; 20:271-3.

48. Breithaupt DE, Kraut S. Simultaneous determination of the vitamins A, E, their esters and coenzyme Q10 in multivitamin dietary supplements using an RP-C30 phase. Eur Food Res Technol 2006; 222:643-9.

49. Bagchi D. Nutraceutical and functional food in the United States and around the world. 2nd Ed. Houston: Academic Press; 2008.

50. Ministério da Saúde. Resolução RDC no 18, de 30 de abril de 1999. Aprova o regulamento técnico que estabelece as diretrizes básicas para análise e comprovação de propriedades funcionais e ou de saúde alegadas em rotulagem de alimentos. Diário Oficial da União 1999; 3 dez.

51. Ministério da Saúde. Resolução RDC no 16, de 30 de abril de 1999. Aprova o regulamento técnico de procedimentos para registro de alimentos e/ou novos ingredientes. Diário Oficial da União 1999; 3 dez.

Recebido em 28/Nov/2014

Versão final reapresentada em 28/Abr/2015

Aprovado em 11/Mai/2015 